Journal of Advanced Research in Fluid Mechanics and Thermal Sciences

Journal homepage: www.akademiabaru.com/arfmts.html ISSN: $2289-7879$

\title{
Heat Transfer Characteristic for Premixed Flame Jet from Swirl Chamber
}

\author{
Nuttamas Uppatam ${ }^{1}$, Wongsathon Boonyopas ${ }^{1}$, Chattawat Aroonrujiphan ${ }^{1}$, Natthaporn \\ Kaewchoothong ${ }^{1}$, Somchai Sae-ung ${ }^{1}$, Chayut Nuntadusit ${ }^{1,2, *}$ \\ Department of Mechanical Engineering, Faculty of Engineering, Prince of Songkla University, Hat Yai, Songkhla 90110, Thailand \\ 2 Energy Technology Research Center (ETRC), Prince of Songkla University, Hatyai, Songkhla 90110, Thailand
}

\section{ARTICLE INFO}

\section{Article history:}

Received 20 December 2020

Received in revised form 31 August 2020

Accepted 31 August 2020

Available online 11 November 2020

Keywords:

Swirling jet; Swirling chamber; Flame

structure; Heat transfer

\section{ABSTRACT}

The objective of this research is to study flame structure and heat transfer characteristics for the premixed flame jet from the swirling chamber. In this study, LPG and air was utilized as gas fuel and oxidizer for a premixed flame. The equivalence ratios $(\phi)$ of $L P G$ and air were considered at $0.8,1.0$, and 1.2 under a Reynolds number $R e=4,000$. The swirl flame was generated by double tangential inlets in cylindrical chamber. The diameter of chamber was fixed at $D=20 \mathrm{~mm}$ and the hydraulic diameter of the inlet was $D_{h}=5 \mathrm{~mm}$. In this study, the effect of chamber geometry on flame structure was investigated by varying the chamber from $H=2.2 D_{h}$ to $7.0 D_{h}$. The structures and temperature of the free flame jet was recorded with camera and measured with a thermocouple. The heat transfer rate of impinging flame jet was also measured at distance from chamber outlet to flame impingement surface varying from $L=4 D_{h}$ to $10 D_{h}$. The results show that the maximum of flame temperature occurs at $\phi=1.2$. Impinging flame jet for case of chamber height at $H=4.6 D_{h}$ and impingement distance at $L=4 D_{h}$ give the highest heat transfer for all equivalence ratios due to the reaction zone of combustion reached to approach near the heat transfer surface.

\section{Introduction}

Impinging flame jets have been extensively used in several industrial applications for heating, grilling or drying process, for examples, annealing of glass, processing of heating and metal and glass including cutting and welding, drying of textiles film and paper [1-4], and drying or grilling of food products [5-8]. The impinging flame jets can produce high heat transfer rate on the impingement surface. However, it demands high fuel consumption for producing a flame jet. Viskanta $[9,10]$ and Tuttle et al., [11, 12] explained that the thermal performance of a flame jet impingement system

\footnotetext{
* Corresponding author.

E-mail address: chayut.n@psu.ac.th
}

https://doi.org/10.37934/arfmts.77.2.3346 
depended on many factors, such as nozzle geometry, fuel-oxidizer type, the flow rate of fuel-oxidizer, impingement surface condition, and configuration between jet nozzle and impingement surface.

Most of past studies focused on a flame jet from the pipe nozzle. The flame jet can locally be heating in the impingement region. The swirling flame jet can be improved a demerit of the nonswirling flame jet from the pipe nozzle. Swirling jet is one of the methods for obtaining uniform heat transfer and higher heat transfer rate on the impingement surface. This is due to the mixing characteristics of the swirling jet promote the spreading rate and turbulence intensity in the jet flow before it impinges on the surface. Recently, many researchers [13-16] studied the flame structure and heat transfer characteristics of swirling flame jet, which generated with different techniques such as twisted tape insert, swirling vane installed in pipe nozzle. Huang et al., [13] studied the heat transfer characteristics of a premixed impinging circular flame jet with induced swirling under the stoichiometric air/fuel condition ( $\phi=1.0$ ) with the Reynolds number varied from $\operatorname{Re}=800$ to 1,700 . They reported that the heat flux on the impingement plate was uniformly and the flame temperatures of the swirling jet became higher than the flame jet without swirling. Zhao et al., [14] evaluated the thermal performance of premixed impinging circular flame jet arrays with induced swirling at $\phi=1.0$ to 1.8 under $\operatorname{Re}=500$ to 2,500 . They concluded that thermal performance increased when the $\operatorname{Re}$ and the $\phi$ increased while it decreased with increasing nozzle-to-plate distance. Zhen et al., [15] studied the emission characteristics of impinging swirling and non-swirling for inverse diffusion flames (IDF) using the hood method. They found that the swirling IDF emitted a reduced quantity of NOx and $\mathrm{CO}$ under most of the experimental conditions. Then, Singh et al., [16] investigated the effect of swirling impinging flame on heat transfer characteristics at $\phi=1.0$ to 1.5 under $\operatorname{Re}=3,500$ to 6,000 . They reported that average heat flux increased significantly with Re while the variation of heat flux was not too considerable with the change of equivalence ratio. Besides, the heat flux distributions on the impingement surface were more uniformly with swirling flame jet as compared to non-swirling flame jet.

Recently, heat transfer characteristics of swirling impinging flame jet using twisted tapes are conducted by Hindasageri et al., [17], who used four twisted types of twist ratios 2, 3.2, 4.5, and 7.5 to obtain the swirling flame jet at $\phi=0.7$ to 1.5 and $R e=500$ to 2,500 . They found that the swirling flame jet could enhance the heat flux by $40-140 \%$ at low Reynolds number. Kotb and Saad [18] compared the thermal and emission characteristics of co-and counter swirl inverse of diffusion flames using liquefied petroleum gas (LPG). The results showed that the centerline temperature profile of the co-swirling IDF was higher than the centerline temperature profile of the counter-swirl IDF for all values of $\phi$ which was used in their study. Kuntikana and Prabhu [19] studied the influence of equivalence ratios on the thermal performance of the Impinging flame jet at $\operatorname{Re}=500$ to 1,000 . They reported that the thermal performance reached a maximum value when the mixture approached stoichiometric condition. Moreover, the burner exit was spaced from the impingement surface such that the premixed cone tip touched the surface. Additionally, the 3D swirling flame structure using stereo-PIV was investigated by Boushaki et al., [20], who employed at the swirl number of 0.8 to 1.4 and the $\phi$ of 0.8 to 1.0. They found that the flame induced a larger radial flow spreading rate with higher mean velocities and higher turbulence intensity in jet structure.

As aforementioned above, the previous studies focused mostly on the effect of burner exit-totarget distance ratio and the equivalence ratios on heat transfer characteristics of the impinging swirling flame jet. However, most of the swirl generators have complex geometry, and some generators are not suitable for utilization in practical industry. In this study, we applied the swirl chamber to generate swirling premixed flame jet by double tangential inlets in a cylindrical chamber. The effect of chamber geometry on the premixed swirling flame structure was investigated by varying the chamber height with fixed chamber diameter and inlet configuration. The heat transfer rate for 
all swirling flame jet was also studied at different jet impingement distances and equivalence ratios between LPG and air.

\section{Experimental Setup and Procedure}

\subsection{Experimental Model and Parameters}

Figure 1 shows the details of a swirling chamber for generating swirling flame jet used in this present work. The swirling chamber has cylindrical geometry and is made of steel pipe having a diameter $(D)$ of $20 \mathrm{~mm}$. The bottom of the chamber has connected to double inlets with a square cross-section. The hydraulic diameter $\left(D_{h}\right)$ of the square tangential pipe was equal to $5 \mathrm{~mm}$. The flow from double inlets was injected tangentially into the main chamber to generate swirl flow in the chamber. The effect of chamber height on the structure of swirling flame jet was investigated by varying at $H=2.2 D_{h}-7.0 D_{h}$.

In this study, the LPG (Propane 70\%, Butane 30\%) and the air was considered as gas fuel and oxidizer for the premixed flame jet. The equivalence ratios $(\phi)$ of 0.8 to 1.2 for LPG-air was varied at $\phi=0.8$ for fuel-lean, $\phi=1.0$ for stoichiometric and $\phi=1.2$ for fuel-rich. All cases of equivalence ratios were conducted at a constant Reynolds number (Re) of 4,000 which based on the mean mixing velocity.

For heat flux measurement of the impinging flame jet, the effect of distance from chamber exit to impingement flat surface was evaluated in the range from $L=4 D_{h}$ to $10 D_{h}$. Likewise, the essential parameters examined in this work were summarized in Table 1.

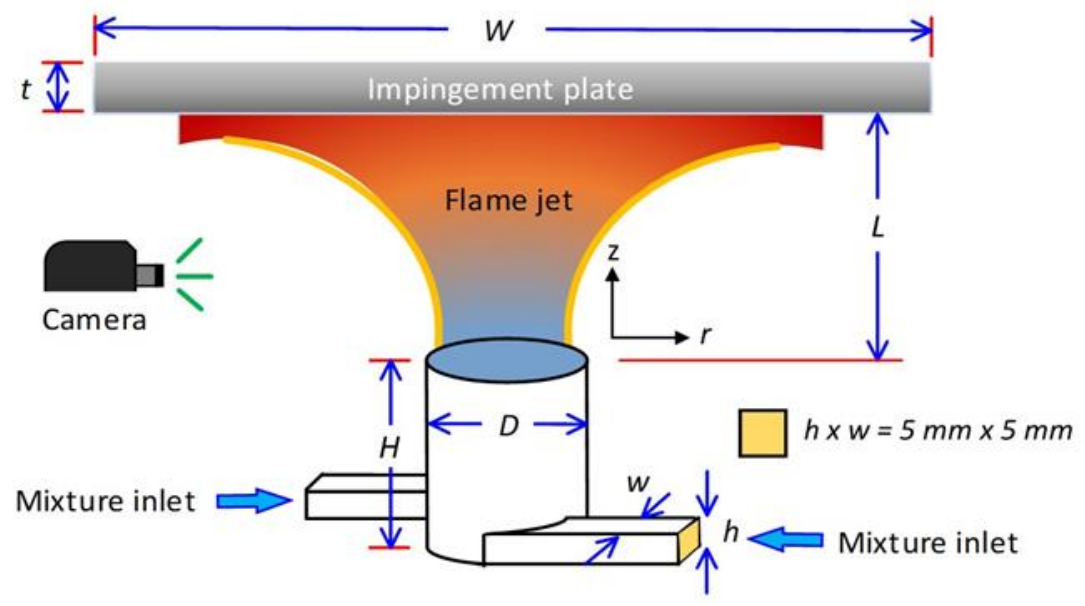

Fig. 1. Details of a swirling chamber used this study

Table 1

Experimental parameters for this study

\begin{tabular}{ll}
\hline Parameters and symbol & Values \\
\hline Diameter of swirl chamber, $D$ & $20 \mathrm{~mm}$ \\
Inlet geometry $(w \times \mathrm{h})$ & $5 \mathrm{~mm} \times 5 \mathrm{~mm}$ \\
Hydraulic diameter of double inlets, $D_{h}$ & $5 \mathrm{~mm}$ \\
Chamber height, $H$ & $2.2 D_{h}, 4.6 D_{h}$, and $7.0 D_{h}$ \\
Chamber exit-to-impingment surface distance, $L$ & $4 D_{h}, 6 D_{h}, 8 D_{h}$, and $10 D_{h}$ \\
Equivalence ratio, $\phi$ & $0.8,1.0$, and 1.2 \\
Reynolds number of LPG-air mixture, Re & 4,000 \\
\hline
\end{tabular}




\subsection{Experimental Apparatus}

Figure 2 illustrates the schematic diagram of an experimental apparatus for this study. The experimental setup was composed of two main parts, viz., flame jet generation part, and impingement plate cooling part.

For the flame jet generation part, LPG gas was supplied from the LPG storage tank. The compressor pump generated the airflow. LPG and air were then passed the pressure regulators with humidity filters and pass through the calibrated rotameters with flow control valves to the mixing chamber. The mixing chamber was installed with some metal balls about $3 / 4$ of the mixing chamber. The diameter of the metal ball was $3 \mathrm{~mm}$. These metal balls are conducive to mixing between LPG and air and also prevent flashback of flame. The pressure of the gas mixture was controlled by 250 Pa before it entered in the swirl chamber.

For impingement plate cooling part, the impingement plate was cooling by circulating the cooling water. Moreover, the heat transfer rate from the impinging flame jet was evaluated from the amount of heat to water. The water from a cooling tank was pumped by a $1 \mathrm{hp}$ of the water pump, and it flowed through the control valve to the rotameter to control the flow rate. Then, it was passed to the temperature control chamber contained with $1300 \mathrm{~W}$ heaters to control the water temperature by using a temperature controller and power controller. Thermocouples type PT-100 was monitored at the chamber outlet. The temperature was controlled at $40^{\circ} \mathrm{C}$ to avoid condensation on the flame impingement surface. After that, the water flowed into the impingement plate. Figure 3 shows the detail of the impingement plate with the cylindrical water chamber. The cylindrical water chamber was made of stainless steel of $150 \mathrm{~mm}$ in diameter and $25 \mathrm{~mm}$ in height. The cylindrical water chamber was fixed by the high-temperature cement insulator of square shape of $20 \mathrm{~mm} \times 20 \mathrm{~mm}$ and a thickness of $25 \mathrm{~mm}$. For measurement, the flame jet impinged on the surface of the cylindrical water chamber. The water inlet and water outlet were on the rear side of the cylindrical water chamber. The rear side was also insulated to protect the heat loss from the water chamber. Furthermore, the digital data logger (midi LOGGER GL840) was used to measure the temperature of water inlet and outlet from the water chamber.

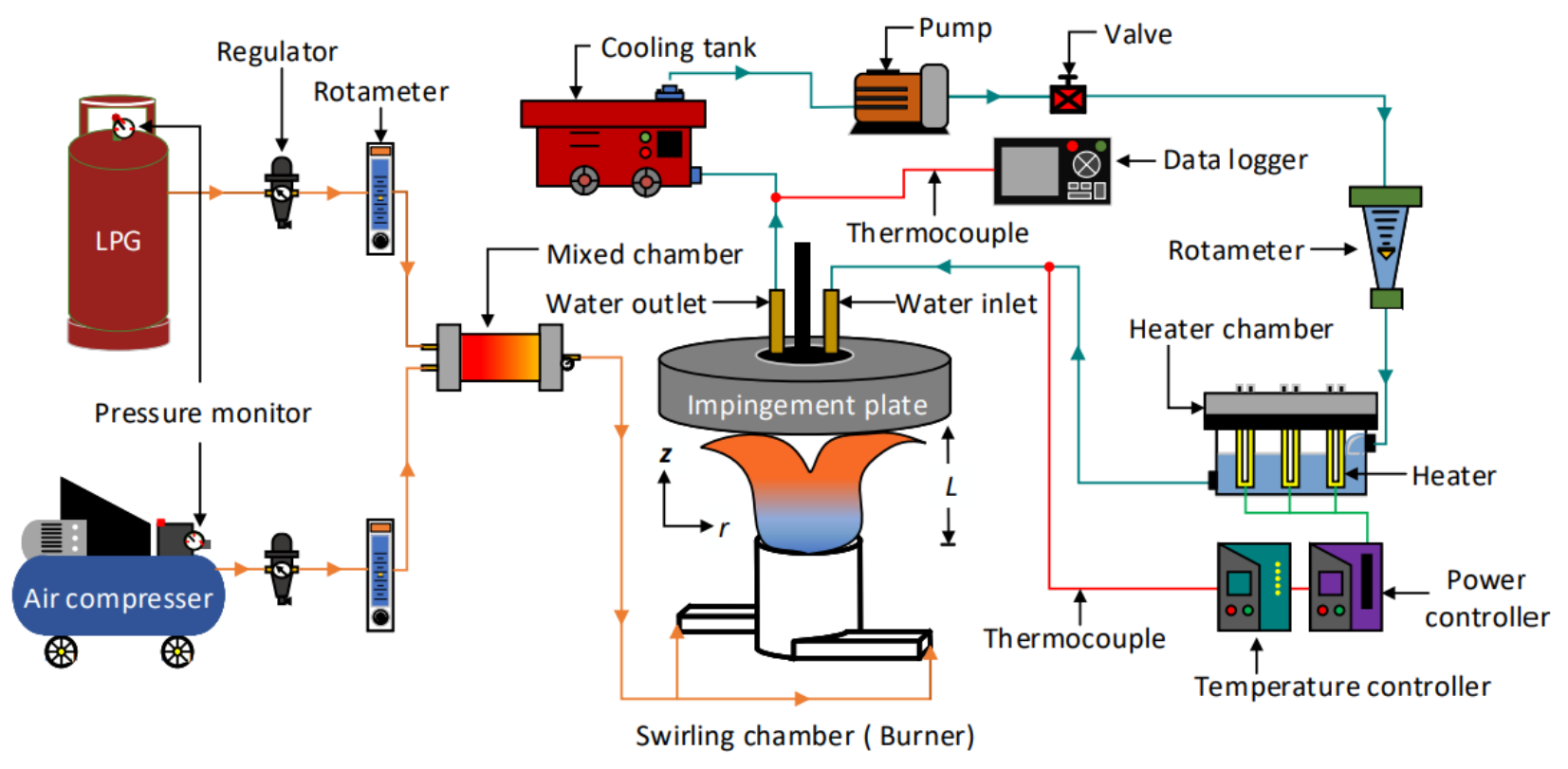

Fig. 2. Schematic diagram of the experiment setup 


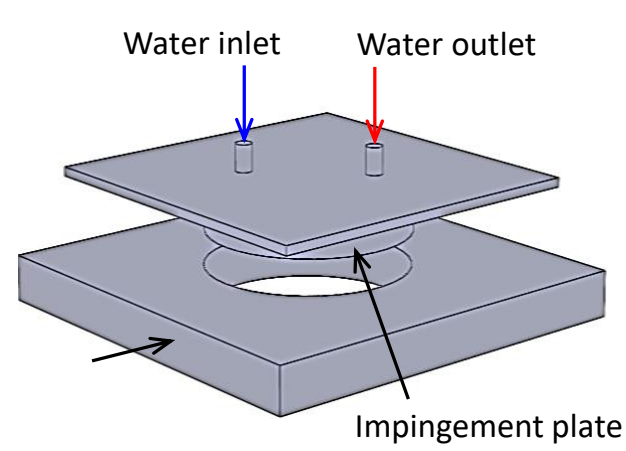

Cylindrical impingement chamber
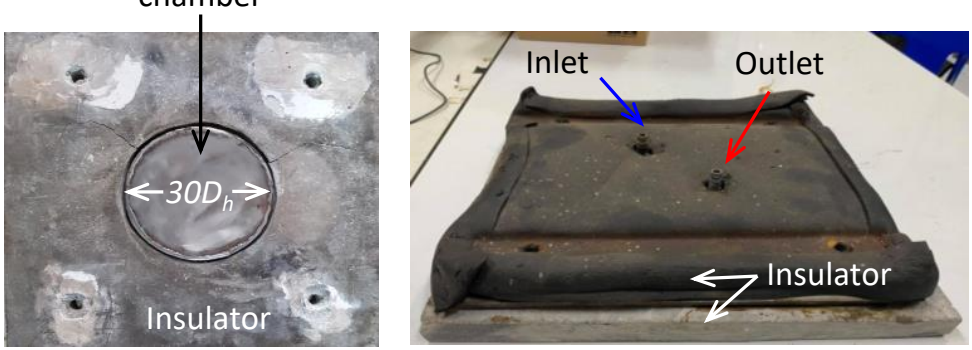

Fig. 3. Detail of impingement plate consisting of cylindrical water chamber equipped in the middle of insulator plate

\subsection{Flame Structure and Average Heat Flux Measurements}

To investigate the structure of swirling flame jet, the free flame jet and impinging flame jet were captured with a digital camera. Moreover, the temperature $\left(T_{f}\right)$ of the free swirling flame jet was measured by a type-B thermocouple (70\% Pt 30\% Rh and 94\% Pt 6\% Rh), which is placed in the flame. Also, this thermocouple was able to adjust the measurement positions on the flame jet region with the $X-Y$ transverse system. For accuracy measurements, the bead thermocouple was considered about the convective and radiative heat losses to surrounding that evaluated with a heat balance correlation of the bead, these suggested by Krishnan et al., [21]. The temperature measurement positions of the swirling flame jet structure in this work were evaluated in the range of $2<Z / D_{h}<10$ and $-2<r / D_{h}<2$, as shown in Figure 4.

For average heat transfer measurement, the temperatures of water inlet and outlet from the cylindrical impingement chamber were monitored by a data logger. When the temperature reached a steady-state, the water temperatures were started to record for 5 minutes (about 300 data). Finally, this information was calculated which leads to the results of average water temperature at inlet and outlet.

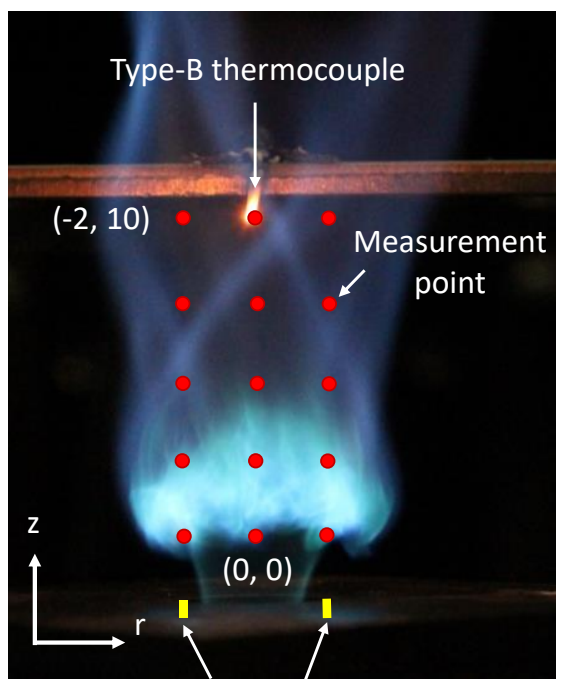

Outlet burners

Fig. 4. Temperature measurement positions in swirling flame jet 


\section{Data Reduction}

All experimental cases for the premixed flame jet of a swirling chamber were carried out at fixed Reynolds number $(\operatorname{Re})$ of 4,000 that depended on the mean mixture velocity $\left(V_{m}\right)$ before entering the swirling chamber, and the hydraulic diameter $\left(D_{h}\right)$ of the inlet.

$$
\begin{aligned}
& R e=\frac{\rho_{m} V_{m} D_{h}}{\mu_{m}} \\
& \mu_{m}=\frac{\sum \mu_{j} X_{j} \sqrt{M_{j}}}{\sum X_{j} \sqrt{M_{j}}} \\
& \rho_{m}=\sum y_{i} \rho_{i}
\end{aligned}
$$

where $\rho_{m}$ is the density of mixture gas between LPG and air, $\mu_{m}$ is the viscosity of mixture gas, $X_{j}$, and $M_{j}$ are respective the mole fraction and the molar mass of component $\mathrm{j}$.

The evaluation of the equivalence ratio $(\phi)$ is as follow

$\phi=\frac{\text { actual fuel / air ratio }}{\text { stoichiometric fuel / air ratio }}$

The average heat flux from a swirling flame jet can calculate from Eq. (5).

$\dot{q}=\frac{\dot{m} C_{p} \Delta T}{A}$

where $\dot{m}$ is the mass flow rate of water, $c_{p}$ is the specific heat of water, $\Delta T$ is the different water temperature between inlet and outlet, and $A$ is the heat transfer area.

The experimental uncertainties were evaluated according to the method described by Moffat [22]. The maximum uncertainty of the Reynolds number and the equivalence ratio was about $4.3 \%$ $4.8 \%$. The uncertainty of temperature recorded with a type-B thermocouple was less than $2 \%$, and heat flux was less than $5 \%$.

\section{Results and Discussion}

\subsection{Flame Structure}

\subsubsection{Flame visualization of the free swirling flame jet}

Figure 5 shows a snapshot photograph of the free swirling flame jet for case of $H=4.6 D_{h}, \varphi=1.0$, and $R e=4,000$. The swirling flame jet structure consisted of three main zones, viz., neck zone, reaction zone and post-combustion flame zone. The neck zone is the region next to the burner exit which the diameter of flame is equal to the chamber diameter. The reaction zone appears next to the neck zone, which chemical reaction of combustion occurs significantly due to intense mixing. And the postcombustion flame zone is the region outside the reaction zone, which the flame jet separated to forming two plumes. The total length of these zones is defined as the flame length $\left(L_{f}\right)$. 


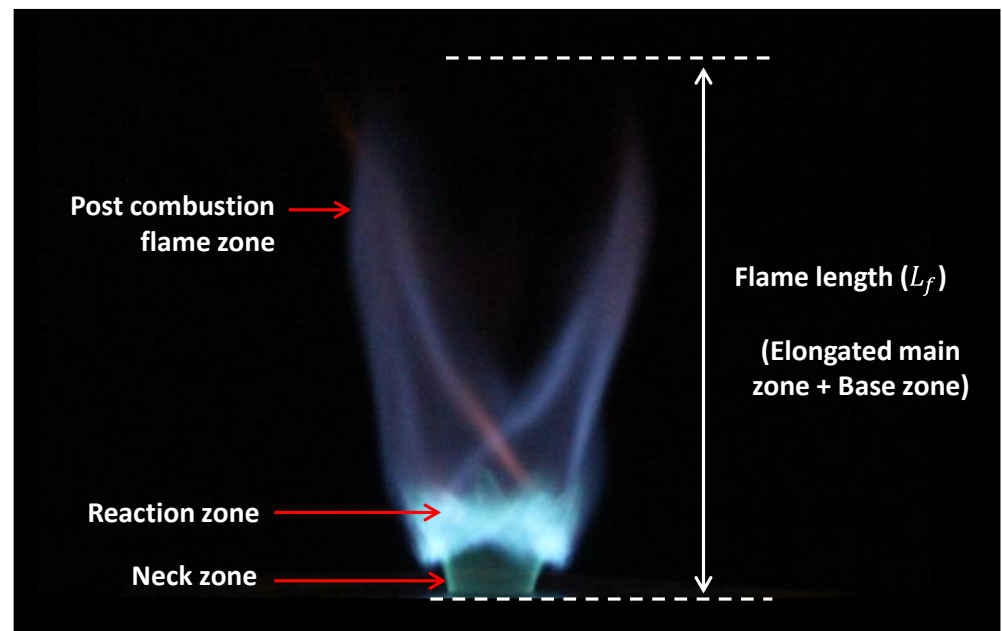

Fig. 5. Snapshot photograph of a free swirling flame jet for case of $H=4.6 D_{h}, \phi=1.0$, and $R e=4,000$

Figure 6 demonstrates some snapshot photographs for the free swirling flame jet. The effect of swirling chamber height and equivalence ratio was shown with varied at $H=2.2 D_{h}, 4.6 D_{h}$, and 7.0D $\phi=0.8,1.0$, and 1.2 under $\operatorname{Re}=4,000$. It is observed that the chamber height provides the effect on the spreading of flame structure and the equivalence ratio, these lead to affect a difference of the size and position of the reaction zone in flame structure.
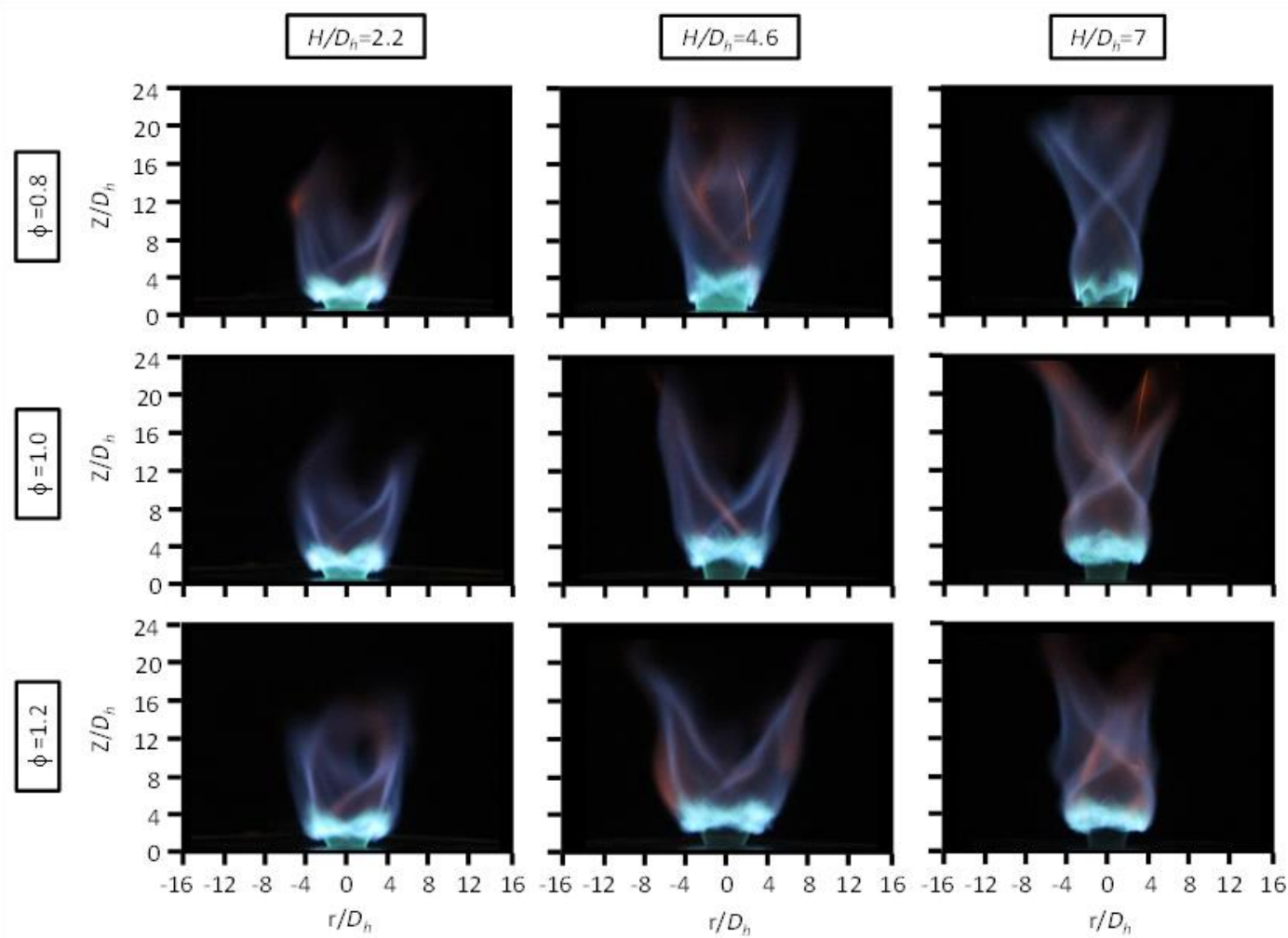

Fig. 6. Comparison of free swirling flame jet structure at different chamber heights $H=$ 2.2D, $4.6 D_{h}$, and $7.0 D_{h}$ and $\phi=0.8,1.0$, and 1.2 under $\operatorname{Re}=4,000$

The post-combustion flame zone covers a more extensive and more extended region when the equivalence ratio $(\phi)$ increases. In case of chamber height $H=2.2 D_{h}$, the post-combustion zone of the flame is the shortest when compared with other cases. Whereas, free swirling flame jet provides 
the longest length when the chamber height $H$ increases because the swirling flow in the chamber was confined and the strength of tangential velocity decreases when compared to the jet axial velocity. The two jets from the double inlets separated clearly and formed two plumes of postcombustion flame zone. The separation between the two jets appears the largest for chamber hight $H=4.6 D_{h}$, especially at $\phi=1.2$. In contrast, the separation becomes narrower at $H=4.6 D_{h}$ and $\phi=$ 0.8. The reaction zone for case of $H=4.6 D_{h}$ will provide the larger area than case of $H=2.2 D_{h}$ and $7.0 D_{h}$, specifically at $\phi=1.0$ and 1.2. Additionally, the results show that the orange flame region will appear in the post-combustion zone when increasing the $\phi$.

\subsubsection{Temperature distributions of free swirling flame jet}

Figure 7 shows the radial temperature distributions in the free swirling jet at a different distance from the chamber exit $Z=2 D_{h}, 4 D_{h}, 6 D_{h}, 8 D_{h}$, and $10 D_{h}$ for different chamber heights $H=2.2 D_{h}, 4.6 D_{h}$, and $7.0 D_{h}$ and $\phi=0.8,1.0$, and 1.2 under $R e=4,000$. It should be noted that the flame temperature is less than the adiabatic flame temperature due to the heat losses to surrounding and air entrainment [23].

The results show that the variation on equivalence ratio from stoichiometric condition to rich or lean mixture condition results in a decrease in the flame temperature. For fuel-lean $(\phi=0.8)$, the flame temperature gives the lowest for all of the chamber height. While, the flame temperature appears at stoichiometric mixture condition $(\phi=1.0)$, especially at $Z=6 D_{h}$ for case of chamber height at $H=4.6 D_{h}$. For fuel-rich $(\phi=1.2)$, the flame temperature gains the highest for all the height of swirl chamber because the swirling flame jet mixed with the surrounding air and the mixing become stoichiometric as going far from the exit.

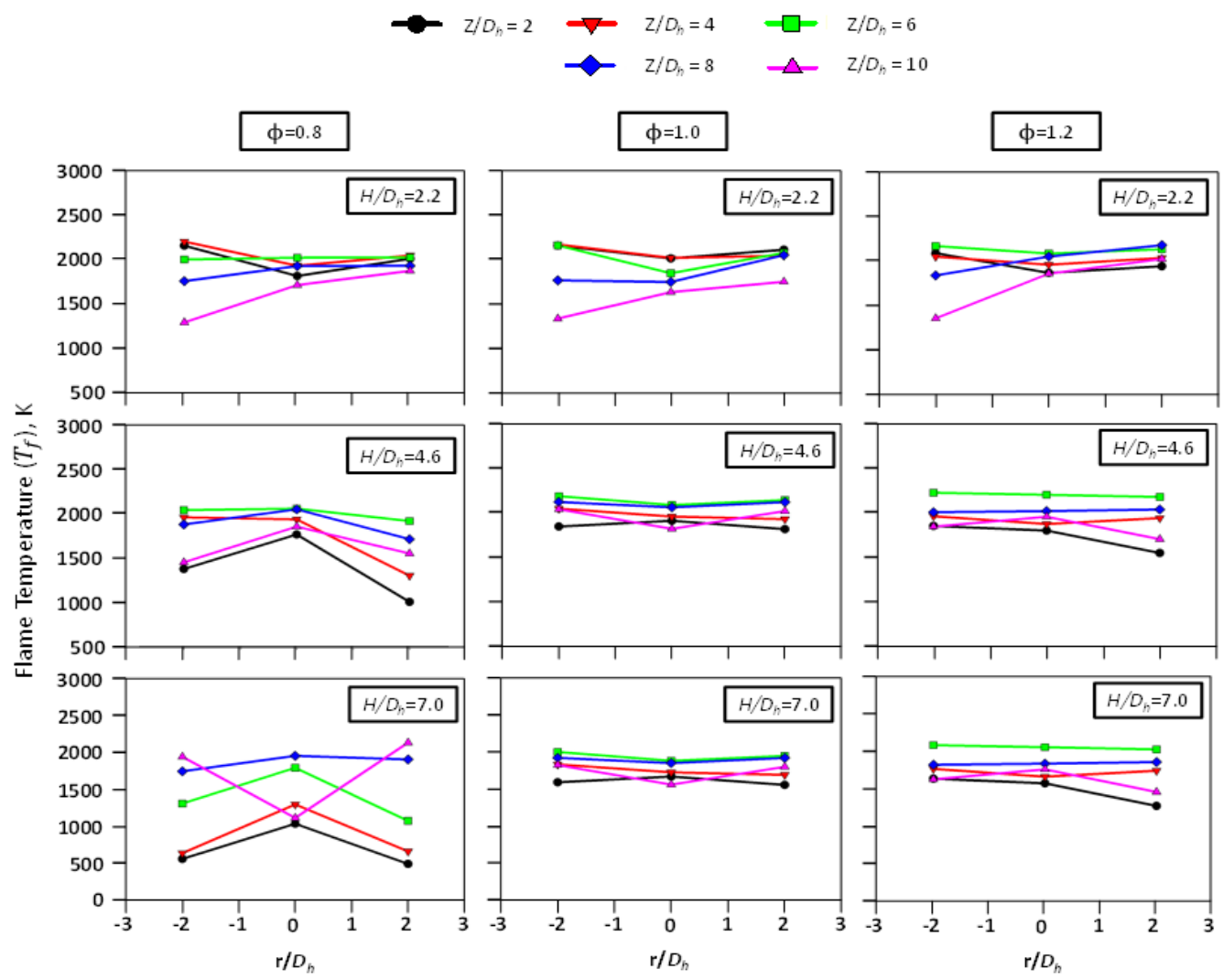

Fig. 7. Comparison of radial temperature distributions in free swirling jet at position $Z=2 D_{h}, 4 D_{h}, 6 D_{h}, 8 D_{h}$, and $10 D_{h}$ for different chamber heights $H=2.2 D_{h}, 4.6 D_{h}$, and $7.0 D_{h}$ and $\phi=0.8,1.0$, and 1.2 under $\operatorname{Re}=4,000$ 


\subsubsection{Flame visualization of impinging swirling flame jet}

To understand the effect of impingement distance on the swirling flame jet impingement structure, Figure 8-11 shows the snapshot photograph of impinging flame jet structure for case $L=$ $4 D_{h}, 6 D_{h}, 8 D_{h}$, and $10 D_{h}$, respectively. Each figure compares the flame structure at different chamber heights $\mathrm{H}=2.2 D_{h}, 4.6 D_{h}$, and $7.0 D_{h}$ and $\phi=0.8,1.0$, and 1.2 under $\operatorname{Re}=4,000$.

For case of $L=4 D_{h}$, the swirling flame jet at chamber height $H=2.2 D_{h}$ spreads on the impingement surface better than case of $H=4.6 D_{h}$ and $7.0 D_{h}$. However, it is found that the reaction zone for case of $H=4.6 D_{h}$ will attach on the impingement surface when the $\phi$ increases. Besides, the results show that the impinging flame jet at $H=7.0 D_{h}$ and $\phi=0.8$ (fuel-lean) spreads over the region between the impingement plate and chamber exit due to the smallest impingement distance and the richest of LPG fuel. This leads to the complex flame structure above the impingement surface.

For case of $L=6 D_{h}$, it is found that the post-combustion zone of flame jet impinges obliquely on the impingement surface. There is no flame impingement on the centre region of the surface for case of $H=2.2 D_{h}$ and $4.6 D_{h}$. This is due to the separated flame jet in the post-combustion zone as found in the free swirling jet. For case of $H=7.0 D_{h}$, the impinging flame jet covers an overall area on the surface. When the equivalence ratio increases, the size of the reaction zone in flame structure increases and approaches the surface as an increase with the chamber height. The flame color on the impingement surface becomes the red-blue color for case of $\phi=1.2$.
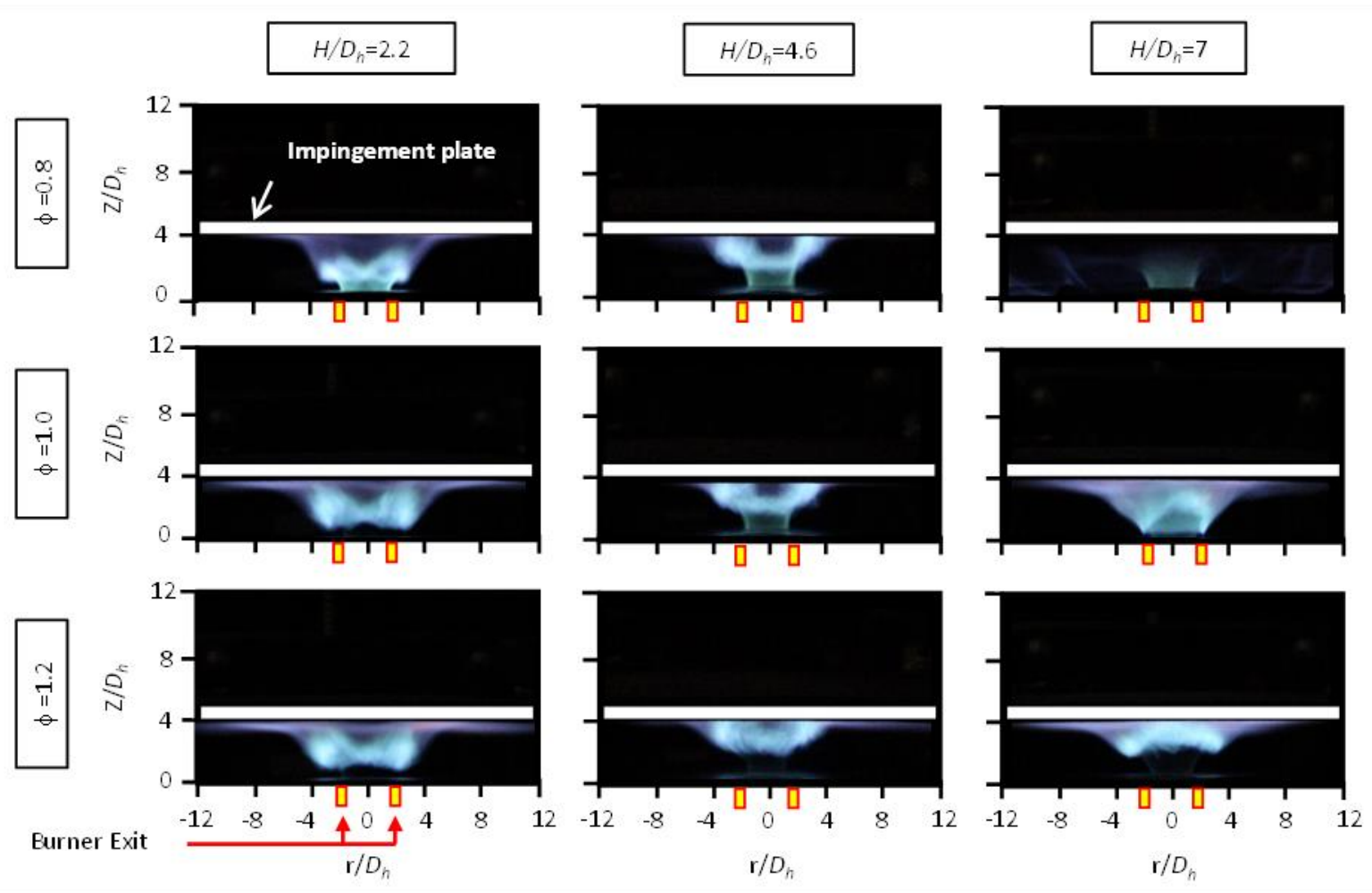

Fig. 8. Comparison of impinging flame jet structure for case $L=4 D_{h}$ at different chamber heights $H=2.2 D_{h}, 4.6 D_{h}$, and $7.0 D_{h}$ and $\phi=0.8,1.0$, and 1.2 under $\operatorname{Re}=4,000$ 

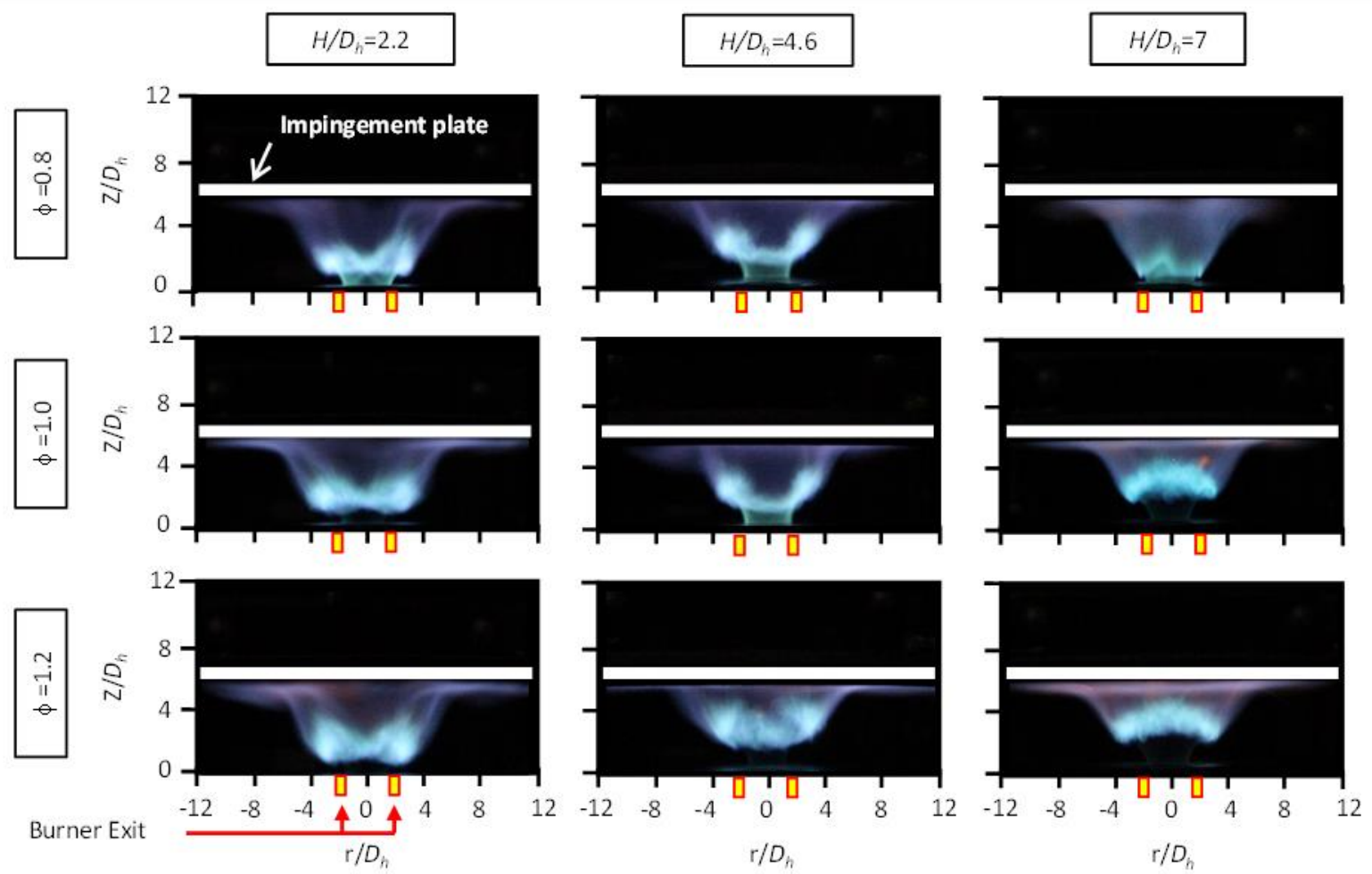

Fig. 9. Comparison of impinging flame jet structure for case $L=6 D_{h}$ at different chamber heights $H=2.2 D_{h}, 4.6 D_{h_{i}}$ and $7.0 D_{h}$ and $\phi=0.8,1.0$, and 1.2 under $\operatorname{Re}=4,000$
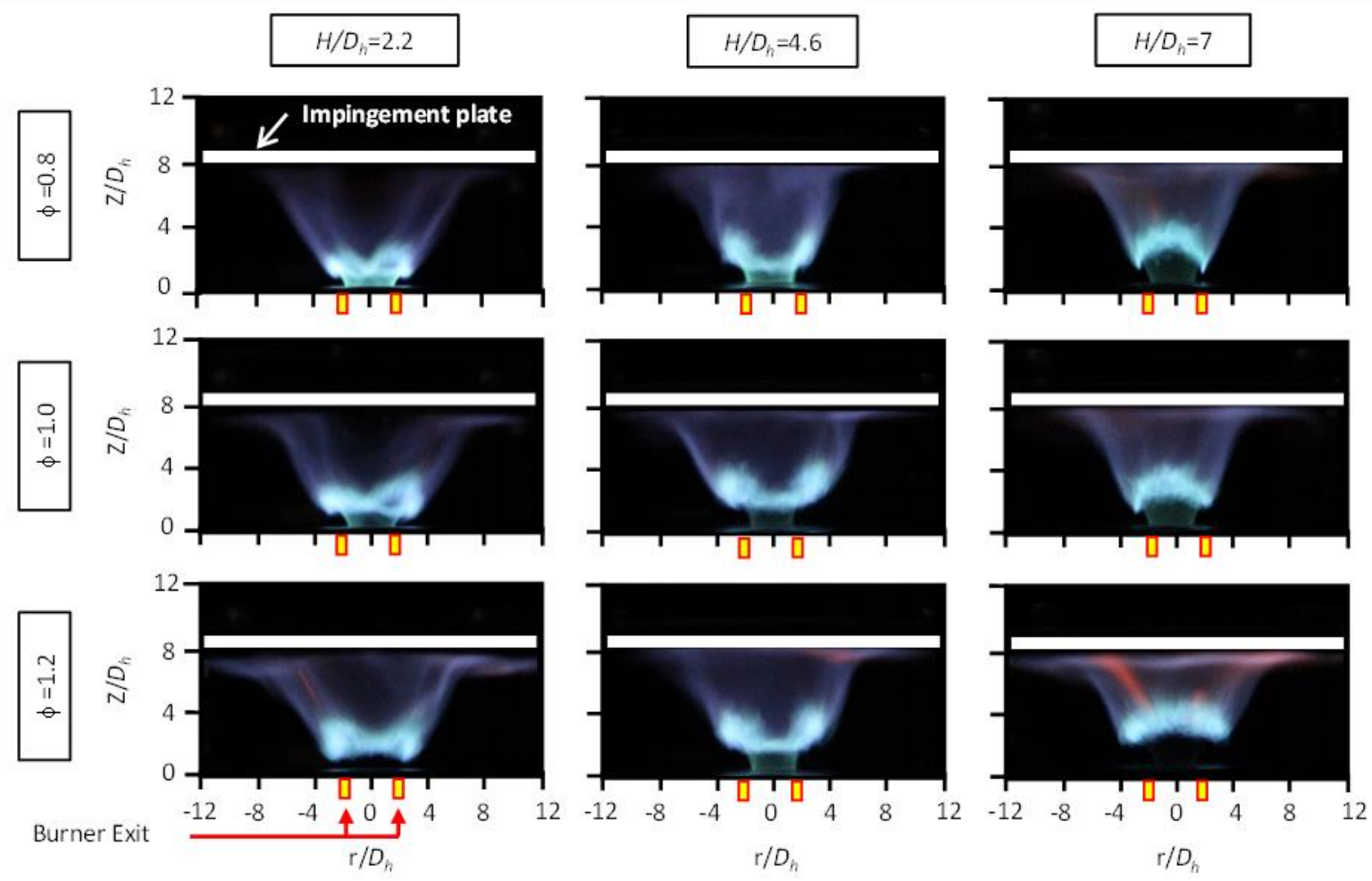

Fig. 10. Comparison of impinging flame jet structure for case $L=8 D_{h}$ at different chamber heights $H=2.2 D_{h}, 4.6 D_{h}$, and $7.0 D_{h}$ and $\phi=0.8,1.0$, and 1.2 under $\operatorname{Re}=4,000$ 
For case of $L=8 D_{h}$, the swirling flame jet in the post-combustion flame zone clearly separated and impinged on the impingement surface. The separation of the two post-combustion zones in flame jet become larger when compared to case of $L=6 D_{h}$. This phenomenon was the same for case of $L=10 D_{\mathrm{h}}$. As increasing the impingement distance, the reaction zone of combustion in all flame structure is farther from the impingement surface. The surface was impinged by the post-combustion zone of the flame jet. Furthermore, it should be noted that the post-combustion zone appears orange in the colour of the flame tip because the combustion was incomplete. Whereas, some swirling flame jet in the post-combustion zone shows blue colour because the surrounding air is more induced into swirling flame when impinging distance increases. This leads to more completed combustion.
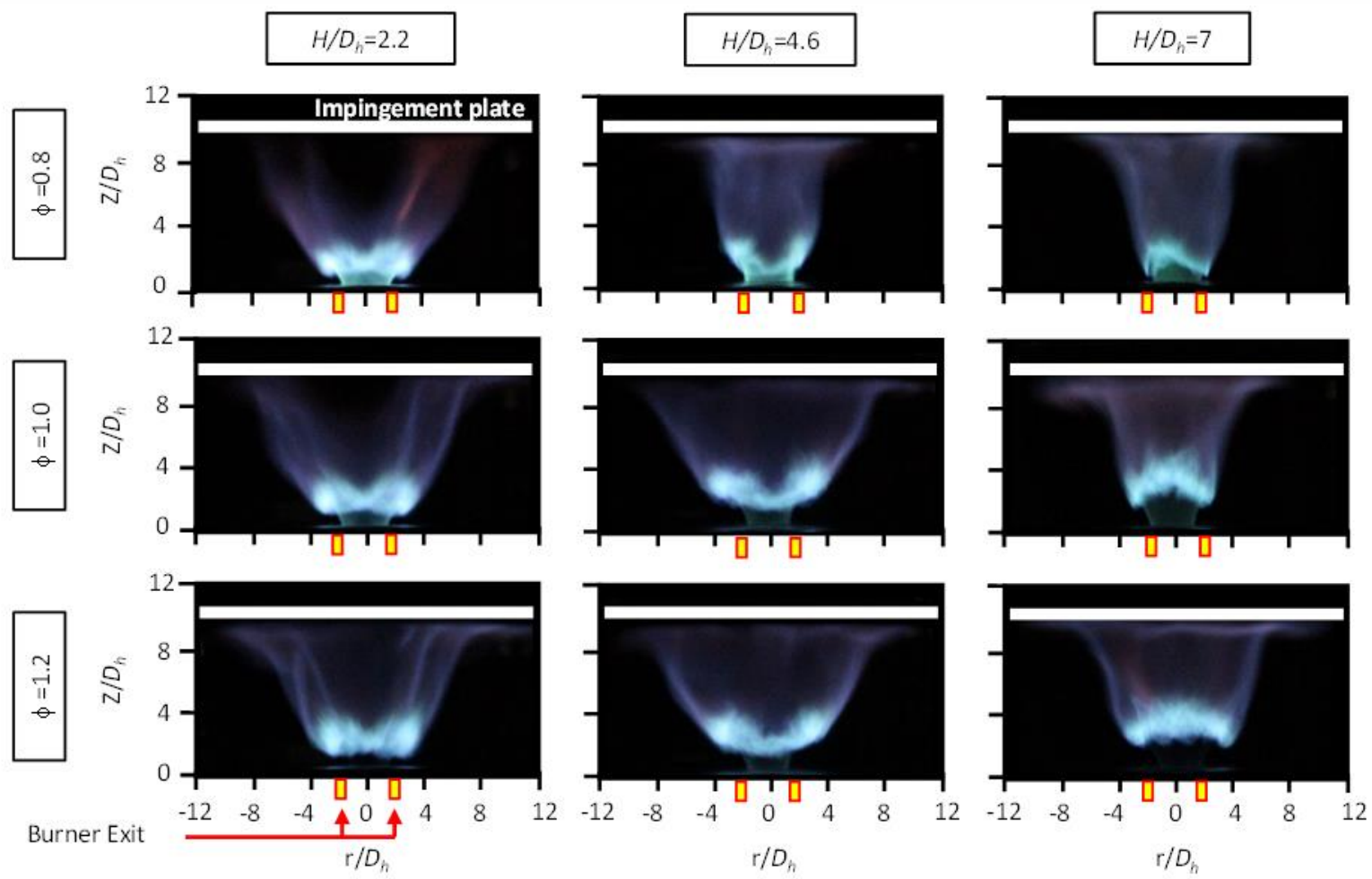

Fig. 11. Comparison of impinging flame jet structure for case $L=10 D_{h}$ at different chamber heights $H=2.2 D_{h}, 4.6 D_{h}$, and $7.0 D_{h}$ and $\phi=0.8,1.0$, and 1.2 under $\operatorname{Re}=4,000$

Figure 12 shows the overall average heat flux for different impingement distance $L=4 D_{h}, 6 D_{h}$, $8 D_{h}$, and $10 D_{h}$ at different chamber heights $H=2.2 D_{h}, 4.6 D_{h}$, and $7.0 D_{h}$ and $\phi=0.8,1.0$, and 1.2 under $\operatorname{Re}=4,000$.

It is found that the average heat flux in case of $H=4.6 D_{h}$ provides the highest for all $\phi$ and chamber height $H$ when compared with other impingement distances, especially at $L=4 D_{h}$ (up to about 10-15\%) because the reaction zone directly exposed on the impingement surface that gives the highest flame temperature. Average heat flux values in case of $H=2.2 D_{h}$ give the lowest for $\phi=1.0$ and 1.2. Whereas, the average heat flux at $\phi=0.8, L=4 D_{h}$ and $6 D_{h}$ in case of $H=7.0 D_{h}$ provide the lowest heat flux as swirling flame structure was short and not attached on the impingement surface. This leads to the lowest heat flux. Moreover, the results show that the average heat flux for fuel-rich $\left(\phi=1.2\right.$ ) produce the highest of above $5-10 \%$ for $L=6 D_{h}, 8 D_{h}$, and $10 D_{h}$. However, it is excepted in a case of $L=4 D_{h}$ when compared to other $\phi$ cases because swirling flame jet in the reaction zone directly impinges and also gain the most uniform heat flux on the impingement surface. 

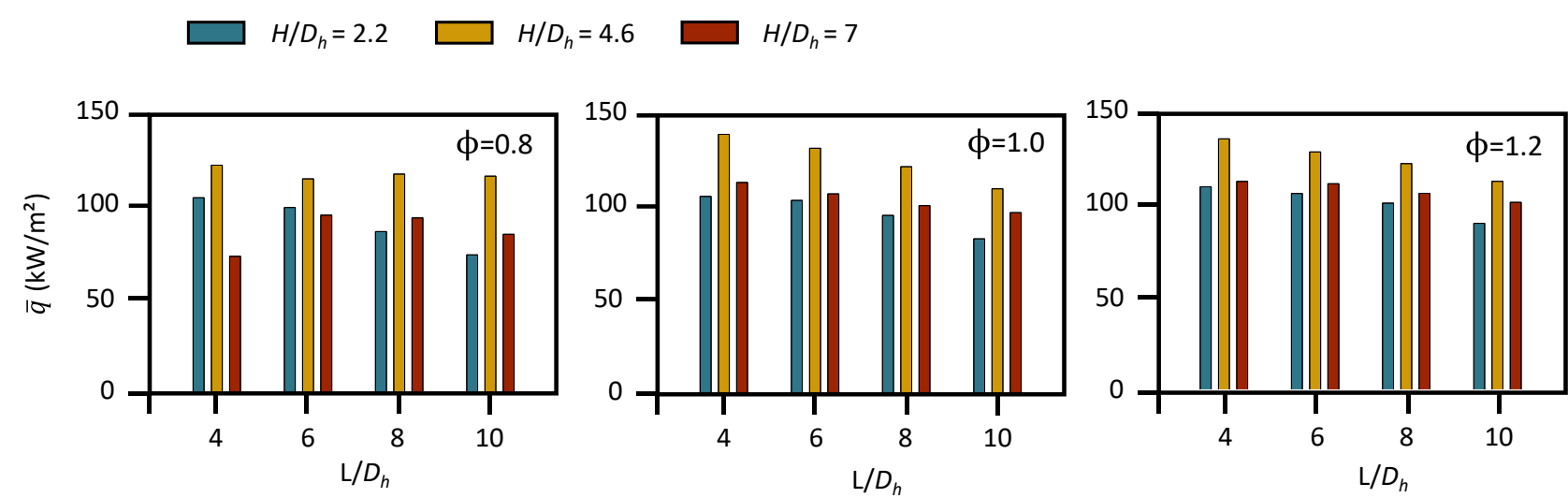

Fig. 12. Comparison of overall average heat flux for different impingement distance $L=4 D_{h}, 6 D_{h}, 8 D_{h}$ and $10 D_{h}$ at different chamber heights $H=2.2 D_{h}, 4.6 D_{h}$, and $7.0 D_{h}$ and $\phi=0.8,1.0$, and 1.2 under $\operatorname{Re}=4,000$

\section{Conclusions}

The main objective of this research was to study the heat transfer characteristics for the premixed flame jet from a swirl chamber. The effect of chamber height on fame structure and heat transfer characteristics were investigated. The effect of equivalence ratios $(\phi)$ was also studied at $0.8,1.0$, and 1.2 for $\operatorname{Re}=4,000$. All experimental results can be concluded as follows

i. The flame structure of both free and impinging flame has been changed significantly, which depends on the chamber height and the impingement distance. Whereas, the reaction zone in the flame structure is the main factor of heat transfer enhancement of impinging jet.

ii. The swirling flame in the reaction zone gives the highest temperature when compared to the other flame zone. Furthermore, the flame temperature at the fuel-lean mixture $(\phi=0.8)$ becomes the lowest while the maximum temperature occurs at the fuel-rich mixture $(\phi=1.2)$ because the swirling flame can induce the ambient air entrainment due to the completed combustion.

iii. The overall average heat flux depends on the chamber height and the impingement distance. The effect of swirling flame can increase the average heat flux on the impingement surface by $10-15 \%$ for case of equivalence ratio $\phi=1.0$, swirling height $H=4.6 D_{h}$ and impingement distance $L=4 D_{h}$.

\section{Acknowledgement}

This research was funded by a grant from the Department of Mechanical Engineering, Faculty of Engineering, Prince of Songkla University, Thailand and by Energy Technology Research Center (ETRC), Prince of Songkla University.

\section{References}

[1] Livingood, J.N.B., and Hrycak, P. "Impingement heat transfer from turbulent air stream jets to flat plates-A literature survey." NASA TM X-2778, (1973): 1-63.

[2] Martin, H. "Heat and mass transfer between impinging gas jets and solid surfaces." Advances in Heat Transfer 13, (1977): 1-60.https://doi.org/10.1016/S0065-2717(08)70221-1

[3] Downs, S.J. and James, E.H., "Jet impingement heat transfer - A literature survey." ASME, AIChE, and ANS, National Heat Transfer Conference and Exhibition, 24 ${ }^{\text {th }}$, Pittsburgh, PA, Aug. 9-12, (1987): 11

[4] Viskanta, R., "Heat transfer to impinging isothermal gas and flame jets." Experimental Thermal and Fluid Science 6, no. 2, (1993): 111-134. https://doi.org/10.1016/0894-1777(93)90022-B 
[5] Sarkar, A., Nitin, N., Karwe, M.V., and Singh, R.P., "Fluid flow and heat transfer in air jet impingement in food processing." Journal of Food Science 69, no. 4, (2004): 113-122.

https://doi.org/10.1111/i.1365-2621.2004.tb06315.x

[6] Kaewchoothong, N., Wae-Hayee, M., Vessakosol, P., Niyomwas, B. and Nuntadusit, C., "Flow and Heat Transfer Characteristics of Impinging Jet from Expansion Pipe Nozzle with Air Entrainment Holes." Advanced Materials Research 931-932, (2014): 1213-1217.

https://doi.org/10.4028/www.scientific.net/AMR.931-932.1213

[7] Nuntadusit, C., Wae-hayee, M. and Kaewchoothong, N., "Heat transfer enhancement on a surface of impinging jet by increasing entrainment using air-augmented duct." International Journal of Heat and Mass Transfer 127, (2018): 751-767.

https://doi.org/10.1016/i.ijheatmasstransfer.2018.06.130

[8] Wae-hayee, M., Yeranee, K., Suksuwan, W., Alimalbari, A., Sae-ung, S., and Nuntadusit, C., "Heat transfer enhancement in rotary drum dryer by incorporating jet impingement to accelerate drying rate." Drying Technology 0, no. 0, (2020): 1-11. https://doi.org/10.1080/07373937.2020.1742150

[9] Viskanta, R., "Heat transfer to impinging isothermal gas and flame jets." Experimental Thermal and Fluid Science 6, no. 2, (1993): 111-134. https://doi.org/10.1016/0894-1777(93)90022-B

[10] Viskanta, R., "Convective and radiative flame jet impingement heat transfer." The Ninth International Symposium on Transport Phenomena in Thermal-Fluids Engineering, (1996): 46-60.

[11] Tuttle, S.G., Webb, B.W., and McQuay, M.Q., "Convective heat transfer from a partially premixed impinging flame jet. Part I: Time-averaged results." International Journal of Heat and Mass Transfer 48, no. 7, (2005): 1236-1251. https://doi.org/10.1016/i.ijheatmasstransfer.2004.10.027

[12] Tuttle, S.G. Webb, B.W., and McQuay, M.Q., "Convective heat transfer from a partially premixed impinging flame jet. Part II: Time-resolved results." International Journal of Heat and Mass Transfer 48, no. 7 (2005): 1252-1266. https://doi.org/10.1016/i.ijheatmasstransfer.2004.10.028

[13] Huang, X.Q., Leung, C.W., Chan, C.K., and Probert, S.D., "Thermal characteristics of a premixed impinging circular laminar-flame jet with induced swirl." Applied Energy 83, no.4, (2006): 401-411. https://doi.org/10.1016/i.apenergy.2005.04.001

[14] Zhao, Z., Yuen, D.W., Leung, C.W., and Wong, T.T., "Thermal performance of a premixed impinging circular flame jet array with induced-swirl." Applied Thermal Engineering 29, no. 1, (2009): 159-166.

https://doi.org/10.1016/i.applthermaleng.2008.02.016

[15] Zhen, H.S., Leung, C.W., and Cheung, C.S., "Emission of impinging swirling and non-swirling inverse diffusion flames." Applied Energy 88, no. 5, (2011): 1629-1634. https://doi.org/10.1016/j.apenergy.2010.11.036

[16] Singh, G., Chander, S., and Ray, A., "Heat transfer characteristics of natural gas/air swirling flame impinging on a flat surface." Experimental Thermal and Fluid Science 41, (2012): 165-176.

https://doi.org/10.1016/j.expthermflusci.2012.04.013

[17] Hindasageri, V., Vedula, R.P., and Prabhu, S.V., "Heat transfer distribution of swirling flame jet impinging on a flat plate using twisted tapes." International Journal of Heat and Mass Transfer 91, (2015): 1128-1139. https://doi.org/10.1016/i.ijheatmasstransfer.2015.08.038

[18] Kotb, A., and Saad, H., "A comparison of the thermal and emission characteristics of co and counter swirl inverse diffusion flames." International Journal of Thermal Sciences 109, (2016): 362-373.

https://doi.org/10.1016/j.ijthermalsci.2016.06.015

[19] Kuntikana, P., and Prabhu, S.V., "Impinging premixed methane-air flame jet of tube burner: thermal performance analysis for varied equivalence ratios." Heat Mass Transfer 55, no. 5, (2019): 1301-1315.

https://doi.org/10.1007/s00231-018-2507-z

[20] Boushaki, T., Merlo, N., de Persis, S., Chauveau, C., and Gökalp, I., "Experimental investigation of $\mathrm{CH}_{4}$-air- $\mathrm{O}_{2}$ turbulent swirling flames by Stereo-PIV." Experimental Thermal and Fluid Science 106, (2019): 87-99. https://doi.org/10.1016/i.expthermflusci.2019.04.026

[21] Krishnan, S., Benjamin, M., Wendong, W.J.U., and Nehorai, A., "An approach to thermocouple measurements that reduces uncertainties in high-temperature environments." Energy \& Fuels 29, (2015): 3446-3455. https://doi.org/10.1021/acs.energyfuels.5b00071

[22] Moffat, R.J., "Describing the uncertainties in experimental results." Experimental Thermal and Fluid Science 1, no.1 (1988): 3-17. https://doi.org/10.1016/0894-1777(88)90043-X 
[23] Law, C.K., Makino, A., and Lu, T.F., "On the off-stoichiometric peaking of adiabatic flame temperature." Combustion and Flame 145, no. 4, (2006): 808-819.

https://doi.org/10.1016/i.combustflame.2006.01.009 